Article

\title{
Production and Optimization of Hermetia illucens (L.) Larvae Reared on Food Waste and Utilized as Feed Ingredient
}

\author{
Anton Gligorescu ${ }^{1, *}$, Christian Holst Fischer ${ }^{1}$, Peter Foged Larsen ${ }^{2}$, Jan Værum Nørgaard ${ }^{3}$ and \\ Lars-Henrik Lau Heckman ${ }^{1,4}$ \\ 1 Division of Environmental Technology, Danish Technological Institute, Kongsvang Alle 29, \\ DK-8000 Aarhus, Denmark; chfi@dti.dk (C.H.F.); 1lh@skov.dk (L.-H.L.H.) \\ 2 HedeDanmark A/S, Klostermarken 12, DK-8800 Viborg, Denmark; pefl@hededanmark.dk \\ 3 Department of Animal Science, Aarhus University, Blichers Allé 20, DK-8830 Tjele, Denmark; \\ janvnoergaard@anis.au.dk \\ 4 Skov A/S, Hedelund 4, Glyngoere, DK-7870 Roslev, Denmark \\ * Correspondence: angl@dti.dk; Tel.: +45-7270-2904
}

Received: 29 October 2020; Accepted: 23 November 2020; Published: 25 November 2020

\begin{abstract}
The feed sector requires new sustainable sources of protein, and at the same time better waste management practices are required to decrease and upcycle post-consumers' food waste (catering and organic household waste), which is currently used for energy production or discharged as waste. The production of Hermetia illucens larvae (L.) (BSFL) was conducted in 15 batches at pilot scale. Furthermore, a feeding strategy experiment was conducted to optimize feedings and decrease handling, followed by a digestibility study for assessing the applicability of BSFL as a feed ingredient. About $190 \mathrm{~kg}$ of food waste was used to produce $79 \mathrm{~kg}$ of BSFL. The bioconversion of food waste into BSFL was found to be highly efficient, with feed conversion rate (FCR) values ranging between 1.7 and 3.6, when assessed on dry matter. The feeding experiment showed similar BSFL and insect frass production as well as similar FCR, revealing that a decrease in handling can be obtained if two feeding episodes are used. The digestibility of protein and fat was high at 86.2 and $90.4 \%$ and revealed that BSFL meal can be successfully used as a protein and fat source in feed for carnivore animals outside the food chain (e.g., pet food).
\end{abstract}

Keywords: food waste; insects; circular economy; sustainability; pilot production; feed application; upcycling

\section{Introduction}

The current food production system is failing to end hunger by 2030 in accordance with the sustainable developmental goal number 2 . In fact, approximately 2 billion people experienced severe and moderate food insecurity in 2019, higher than in 2014 [1]. However, global food insecurity is mainly associated with limited access to nutritious and sufficient food, food losses and waste [1], rather than being a consequence of an overall global food shortage [2].

Approximately 1.6 billion tons of the produced food is lost and wasted annually, from which 1.3 billion tons is edible. This waste leads to high environmental impacts being the third largest $\mathrm{CO}_{2}$ emitter after USA and China. Moreover, approximately $250 \mathrm{~km}^{3}$ of fresh water and $30 \%$ of the total agricultural land are used to produce food which then is wasted. Furthermore, high losses in biodiversity and natural ecosystem function are associated with monoculture practices and agricultural expansion. In consequence, overall food waste and loss is an important contributor to climate change. While food loss occurs during production, storage and distribution, food waste occurs at the retail or 
consumer level [3]. However, the highest waste of food is seen in developed countries at consumer level where approximately $95-115 \mathrm{~kg}$ of food/capita/year is wasted [4].

Following the global tendence, the import of protein sources used in animal production in Denmark is linked to high environmental and socio-economic impacts and consequently to climate change [5]. Furthermore, Denmark is an important producer of food waste in Europe with an estimate of food waste of around 1.1 million tons generated in 2016 [6]. In order to address waste production, including food waste, the Danish Government developed the Resource Strategy for Waste Management which aims among other goals to optimize the use of resources, improving recycling and energy recovery across different industries under the Circular Economy paradigm [7].

New systems, which can recover protein and fat from food waste and further utilize them as feed sources, can help decreasing environmental impacts and food waste at both local and global levels. Such a system is insect bioconversion, which can up-cycle viable nutrients and energy from waste streams such as food waste into high protein and fat larval biomass suitable for animal feed [8]. Among the most promising insect species for bioconversion of food waste is Hermetia illucens (Black Soldier Fly (BSF)). BSF is a holometabolous Diptera specie, native to Neotropics and currently spread across the temperate and tropical regions [9]. BSF is known to only feed during the larval stage, while the adult serves only reproductive purposes and, therefore, is not considered a pest [10]. In the natural habitat, a female BSF lays eggs in the vicinity of decomposing materials. After emerging from the eggs, the larvae of BSF actively feed on the decaying materials until they reach the prepupa stage, when they migrate outside the decaying materials and find shelter and drier vegetation, where pupation is initiated. Consequently, metamorphosis occurs, and the life cycle is repeated. [11] Numerous studies find that BSF larvae (BSFL) can successfully bioconvert different low-value organic side streams into high protein and lipid larval biomass that can be used as animal feed [12-17]. According to Lalander et al. (2019), the BSFL can be used in the management of different waste streams including: abattoir waste, food waste, human feces and a mixture of: abattoir waste, fruits and vegetables [12]. Furthermore, the utilization of BSFL for the management of other waste streams including manure (poultry and swine), biogas digestate, vegetable and fruit wastes and municipal waste were previously documented and discussed in multiple review articles $[13,14]$. Similarly, the utilization of BSFL as feed for poultry, swine and in aquaculture is extensively covered and discussed in multiple reviews [15-17]. Previous studies have demonstrated that the production of BSFL protein has lower environmental impact than the conventional sources of protein (fishmeal), making this a promising source of sustainable protein [18]. However, further research and local governmental support in the form of $R \& D$ grants are required to fully assess the potential of producing insects on waste streams, such as former foodstuffs, catering waste and organic household waste, not least to document overall safety.

The present study was conducted as part of the Waste, Insects and Circular Economy (WICE) project funded by the Danish Environmental Protection Agency's Environmental Technology Development and Demonstration Program (MUDP) and was conducted between 2017 and 2019. The project had the scope to demonstrate the potential of up-cycling organic household waste and catering waste into high-quality macronutrients in the form of insect biomass, suitable to be used as a feed source. The nutrient digestibility of BSFL was addressed in a study using mink (Neovison vison (L.)). The mink is a potential consumer of BSFL, since it is outside the food chain and thus legally can be fed insects, but the mink also serves as a model animal for other carnivorous animals such as pets and fish. To achieve the scope of the project, a pilot production of BSFL was established, and a series of experiments for optimizing the production and testing the utilization of BSFL biomass as a feed ingredient outside the food chain were conducted. 


\section{Materials and Methods}

\subsection{Insect Production and Optimization}

\subsubsection{Pilot Production}

The production of BSFL was conducted at the Danish Technological Institute (DTI) for a period of 14 months during which the BSFL were fed on food waste in the form of biopulp provided by the waste management company KomTek (Holsted, Denmark). The food waste was introduced to a pulper with initial addition of water. After approximately $30 \mathrm{~min}$ of pulping, the material was passed through a sieve $(6 \mathrm{~mm})$ and separated into an organic pulp (biopulp) and a rejected solid fraction consisting of particles larger than $6 \mathrm{~mm}$. Consequently, the biopulp was concentrated using a screw separator, before being partly fermented (pH of approx. 4). The juvenile larvae (approximately 6 days old) used in the production were provided by InsektProtein IVS, Sønderborg, Denmark. Fifteen batches of BSFL were addressed in the current study. The individual batches were defined based on different dates of production. The biopulp was stored in a freezer at $-22{ }^{\circ} \mathrm{C}$ until used in the production. Samples from the biopulps were taken, weighed and placed in an oven at $105^{\circ} \mathrm{C}$ for at least $24 \mathrm{~h}$ before weighing them again to determine the dry matter (DM) content of the biopulp of individual batches (Table 1). Since the biopulp DM was found to be very low, this was corrected by the addition of a commercial compound chicken feed (88\% DM) as presented in Table 1.

Table 1. Composition (\%) of diets including biopulp and chicken feed used in the production of different batches (B), and the dry matter (DM) of biopulp before and after correction with chicken feed.

\begin{tabular}{ccccc}
\hline Batches & Biopulp & Chicken Feed & DM Biopulp & DM after Correction \\
\hline & $\mathbf{( \% )}$ & $\mathbf{( \% )}$ & $\mathbf{( \% )}$ & $\mathbf{( \% )}$ \\
\hline B 1 & 99 & 1 & 22 & 23 \\
B 2 & 93 & 7 & 15 & 22 \\
B 3 & 95 & 5 & 15 & 21 \\
B 4 & 93 & 7 & 15 & 23 \\
B 5 & 97 & 3 & 15 & 19 \\
B 6 & 97 & 3 & 15 & 18 \\
B 7 & 98 & 2 & 14 & 17 \\
B 8 & 97 & 3 & 14 & 17 \\
B 9 & 98 & 2 & 14 & 16 \\
B 10 & 96 & 4 & 14 & 17 \\
B 11 & 97 & 3 & 14 & 15 \\
B 12 & 99 & 1 & 13 & 20 \\
B 13 & 96 & 4 & 16 & 17 \\
B 14 & 96 & 4 & 13 & 16 \\
B 15 & 99 & 1 & 14 & \\
\hline
\end{tabular}

The production batches were carried out in crates of $60 \times 40 \times 15 \mathrm{~cm}(4-14 \mathrm{crates} / \mathrm{batch})$ and maintained under laboratory conditions (i.e., ambient temperature: approximately $27^{\circ} \mathrm{C}$; relative humidity (RH): approximately $60-70 \%$ ). Around 20,000 juveniles were weighed and transferred to individual crates and fed with a total of $8-10 \mathrm{~kg}$ of fresh weight (FW) biopulp per crate until first prepupa larvae (dark color) were observed 8-10 days later. Similar to the case of biopulp, the DM content and the juveniles' biomass (FW and DM) used to produce individual batches were determined.

After 8-10 days, the larvae from individual crates were separated from the insect frass (digested and undigested substrate), using a sieve crate $(60 \times 40 \times 10 \mathrm{~cm})$ with holes of $4 \mathrm{~mm}$ in diameter, and weighed to determine the larval biomass. Furthermore, a sample of larvae was taken from each crate and was used to determine the larval DM content and consequently the larval dried biomass from each crate. Based on the data from individual production crates (larval biomass and DM content), the larval biomass (FW and DM) for each production batch was determined. 
The total biomasses (TB) of biopulp after correction and of larvae from individual, subsequent batches were added up in order to calculate the accumulated biomasses (ACB) over 15 production batches. This was carried out by adding the biomasses from previous batches to the last archived batch. Furthermore, the biopulp, larval and juvenile biomasses were used to determine the feed conversion rate (FCR) for each production batch on both a DM to DM and DM to FW basis according to Oonincx et al. (2015) [19].

\subsubsection{Feeding Optimization}

During the pilot production, a series of experiments were conducted to optimize the production of BSFL and to reduce the cost of the production. Among these, a feeding experiment was conducted, and the data from this experiment are addressed in the present study. The feeding experiment was conducted during the production of Batch 12 and consisted of 2 feeding treatments and 3 replicates, as presented in Table 2.

Table 2. Different feeding strategies tested during the production of Batch 12.

\begin{tabular}{cccccccc}
\hline Treatments & Day 0 & Day 3 & Day 5 & Day 6 & Day 8 & & Day 10 \\
\hline & Bio-Pulp & Bio-Pulp & Bio-Pulp & Bio-Pulp & Bio-Pulp & Chicken Feed * & Total \\
\hline [Kg FW] & [Kg FW] & [Kg FW] & [Kg FW] & [Kg FW] & [Kg FW] & [Kg FW] \\
\hline Two feedings & 5.22 & & & 3.34 & & 0.15 & 8.71 \\
Two feedings & 5.20 & & & 3.36 & & 0.15 & 8.71 \\
Two feedings & 5.22 & & & 3.34 & & 0.15 & 8.71 \\
Five feedings & 3.20 & 1.00 & 1.00 & 1.40 & 1.96 & 0.15 & 8.71 \\
Five feedings & 3.20 & 1.00 & 1.02 & 1.40 & 1.94 & 0.15 & 8.71 \\
Five feedings & 3.20 & 1.00 & 1.00 & 1.40 & 1.96 & 0.15 & 8.71 \\
\hline
\end{tabular}

* The chicken feed was mixed with the biopulp before being used in the production.

As in the case of pilot production, about 20,000 juveniles were weighed (approximately $100 \mathrm{~g} \mathrm{FW}$ ), placed in individual crates, fed with biopulp and chicken feed (Table 2) and maintained under stable laboratory conditions (ambient temperature: $27^{\circ} \mathrm{C}$ and RH: $60-70 \%$ ) for 10 days until first prepupa was observed. Consequently, the larval biomass and insect frass belonging to individual crates were separated and weighed (g FW).

The DM content (\%) of biopulp, juveniles, as well as larvae and insect frass post separation was analyzed based on individual samples and used to determine the DM biomass (g) of biopulp, juveniles, larvae and insect frass for each crate (Table 3). Data were further used to determine the FCR (DM basis) of the system as well as to determine the consumption rate biomass reduction (DM) $[19,20]$. Individual samples from the biopulp, chicken feed and BSFL belonging to each treatment were taken and used to analyze their crude protein and fat content. Moreover, the protein and fat content of six-day-old juveniles estimated by Liu et al. (2017) was used [21] (see Table 3).

Table 3. Dry matter (DM), ash and macronutrient content of biopulp, chicken feed, juveniles and Hermetia illucens larvae (BSFL) (\%).

\begin{tabular}{cccccc}
\hline & Bio-Pulp & Chicken Feed & Juveniles * & BSFL 2 Feedings & BSFL 5 Feedings \\
\hline DM (g/100g) & 13.4 & 88.0 & 19.8 & 32.7 & 30.8 \\
Crude protein & 25.4 & 21.0 & 54.2 & 32.5 & 35.1 \\
Fat & 17.2 & 4.1 & 9.6 & 26.0 & 27.9 \\
Ash & 2.4 & 6.0 & 3.2 & 5.9 & 5.7 \\
\hline \multicolumn{5}{c}{}
\end{tabular}

The protein data were used together with data from DM biomass estimations to calculate the crude protein of biopulp and chicken feed as well as juveniles and BSFL at harvest for individual replicates 
and consequently to estimate the protein conversion efficiency (PCE) of the system, using Equation (1) according to Nalawade et al. (2014) [22]:

$$
\mathrm{PCE}=\text { Larval gained protein }(\mathrm{g}) / \text { Feed protein }(\mathrm{g}) * 100
$$

\subsection{Digistability Study}

\subsubsection{Design of the Experiment}

The digestibility study was conducted using the regression method design with mink which was chosen as a model animal for carnivore animals. The experiment was carried out by Kopenhagen Fur at their R\&D facility in Holstebro, Denmark. The experiment consisted of 4 dietary treatments (1 control and 3 BSFL inclusion diets) of 3 replicates, each consisting of three adult males. The BSFL were chopped and then heat treated at $80^{\circ} \mathrm{C}$ for $30 \mathrm{~min}$ before being stored in a freezer at $-22{ }^{\circ} \mathrm{C}$ prior to being used. The dietary treatments were developed by substituting cod filet with BSFL at different rates (low, medium and high) (Table 4).

Table 4. Ingredient content (\%) used in the development of 3 BSFL inclusion diets and a control diet (before water correction).

\begin{tabular}{ccccc}
\hline Ingredients $(\mathbf{\%}$ FW) & Control & Low Inclusion & Medium Inclusion & High Inclusion \\
\hline BSFL & 0.0 & 4.4 & 8.9 & 13.5 \\
Cod filet & 81.6 & 79.5 & 75.7 & 71.9 \\
Soy oil & 8.4 & 6.7 & 6.1 & 5.5 \\
Cornstarch & 8.6 & 7.7 & 7.6 & 7.5 \\
Dextrose & 1.0 & 1.0 & 1.0 & 1.0 \\
Cellulose & 0.5 & 0.5 & 0.5 & 0.5 \\
Vitamins and minerals & 0.2 & 0.2 & 0.2 & 0.2 \\
\hline
\end{tabular}

All ingredients were analyzed for protein and fat, and the results from the analysis were used to ensure that the dietary treatments had similar macronutrient content but increasing contribution of protein from BSFL. Moreover, the DM and ash contents of the developed diets were analyzed and corrected by the addition of water in order to ensure similar levels (Table 5).

Table 5. Dry matter (DM), ash and macronutrient contents of BSFL and dietary treatments (\%).

\begin{tabular}{cccccc}
\hline Content & BSFL & Control & Low Inclusion & Medium Inclusion & High Inclusion \\
\hline DM $(\mathrm{g} / 100 \mathrm{~g})$ & 42.8 & 27.9 & 27.3 & 26.1 & 27.4 \\
Crude protein & 20.1 & 12.8 & 12.3 & 12.2 & 12.9 \\
Fat & 15.5 & 7.1 & 5.9 & 5.2 & 5.2 \\
Carbohydrate * & 6.0 & 7.2 & 8.1 & 7.7 & 8.1 \\
Ash & 1.2 & 0.8 & 1.0 & 1.0 & 1.2 \\
\hline
\end{tabular}

* Carbohydrate is calculated by proximate analysis as being the remainder of the dry matter when the amount of crude protein, crude fat and crude ash is deducted.

The mink were transferred into individual experimental balance cages and fed with different dietary treatments $(1255 \mathrm{~kJ} /$ day) for a 7-day adaptation period. All mink were found to feed on the diets by the third day, except for two. These two males were replaced, and the mink were further observed until day 7 when all mink were actively feeding. Similarly, as during the adaptability period, the mink were fed the dietary treatments $(1255 \mathrm{~kJ} /$ day $)$ for a 4-day collection period. The food intake and feces collection were recorded daily, and samples of feces belonging to each treatment were taken and analyzed for their DM, crude protein, fat and ash content. Furthermore, the collected feces from different treatments were scored according to their physical characterization: from solid (score 1) to aqueous (score 6). 


\subsubsection{Chemical Analysis}

All ingredients, dietary treatments and feces samples were analyzed for DM crude protein, fat and ash. The crude protein was determined using the Kjeldahl method, and the fat content was determined using the gravimetric method. Moreover, the DM and ash contents were determined by weighing the sample before and after being stored at 105 and $550{ }^{\circ} \mathrm{C}$, respectively, for at least $24 \mathrm{~h}$ until constant weight.

Based on the collected feces, feed intake and the results from the analysis, the digestibility for crude protein, fat and carbohydrate nutrients was calculated. Since mink are not able to digest cellulose, the estimated digestibility of carbohydrate was corrected for this by subtracting the assigned cellulose amount from both feed and feces before calculating digestibility.

\subsection{Statistical Analysis}

The statistical analysis of the feeding experiment was conducted in Excel 2019. The analysis consisted of a $t$-test $(p<0.05)$ for assessing the difference between different feeding strategies on a series of parameters: BSFL and insect frass biomass, FCR, biomass reduction and PCE. The equality of variances was tested for all parameters, using an F-test $(p<0.05)$.

The statistical analysis of digestibility study was carried out with PROC REG in SAS. The analysis of digestibility of BSFL consisted of a regression line analysis where the increasing contributions by BSFL of crude protein, fat and carbohydrates in the diets were extrapolated to $100 \%$. The carbohydrate fraction was subtracted for the contribution of supplemented cellulose. Cook's Distance was used to identify potential outliers, and one observation from the fat regression analysis was excluded from the analysis.

\section{Results}

\subsection{Pilot Production and Feeding Experiment}

Overall, the production of BSFL on food waste was found to be highly efficient and constant. The production of BSFL on biopulp was found to be stable with low fluctuation, where $190 \mathrm{~kg}$ DM of biopulp was successfully up-cycled into $79 \mathrm{~kg}$ BSFL DM biomass (Figure 1).

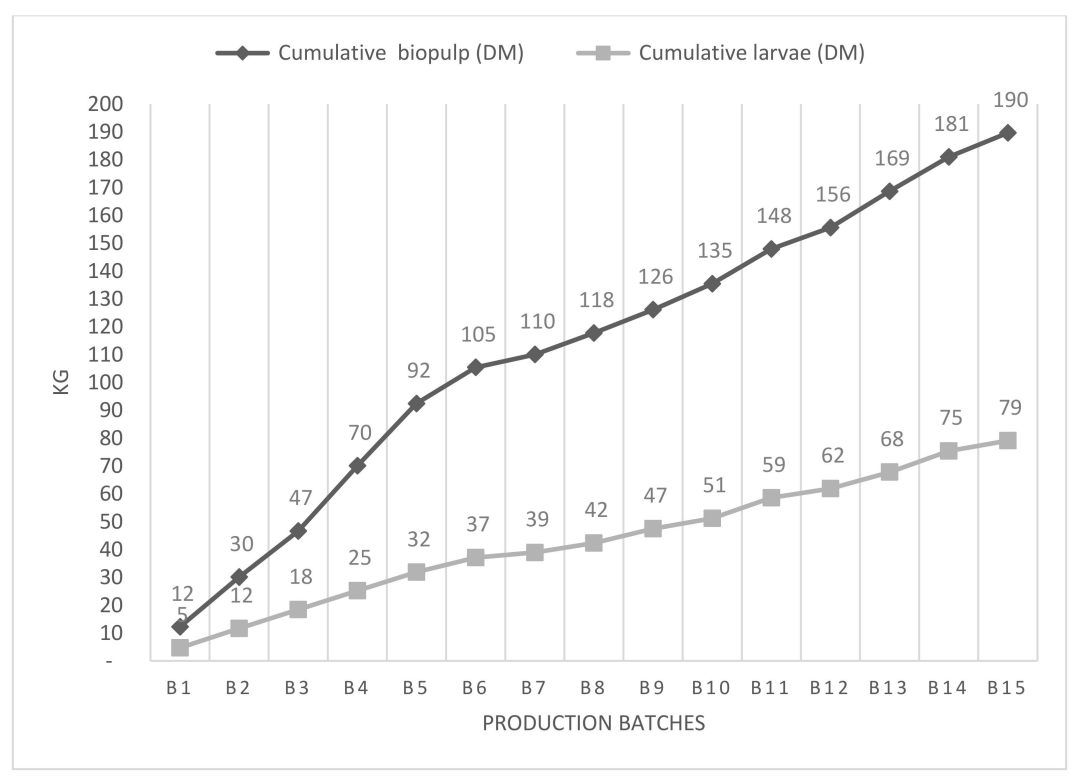

Figure 1. Cumulative biopulp utilized and larval biomass produced over 15 production batches (B1 to B15). The biopulp and larval biomass are displayed on a dry matter (DM) basis. 
Overall low FCR values were obtained during the production, with values ranging between 1.7 and 3.6 when assessed on a DM/DM basis and between 0.5 and 1.1 when assessed on an FW/DM basis The FCR was found to experience a higher variation (FCR: 2.6-3.6 (DM/DM)) in the beginning of the production (batches 1-5) and become more stable (FCR: 1.7-2.9 (DM/DM)) in the second part of the production period (batches 6-15) (Figure 2).

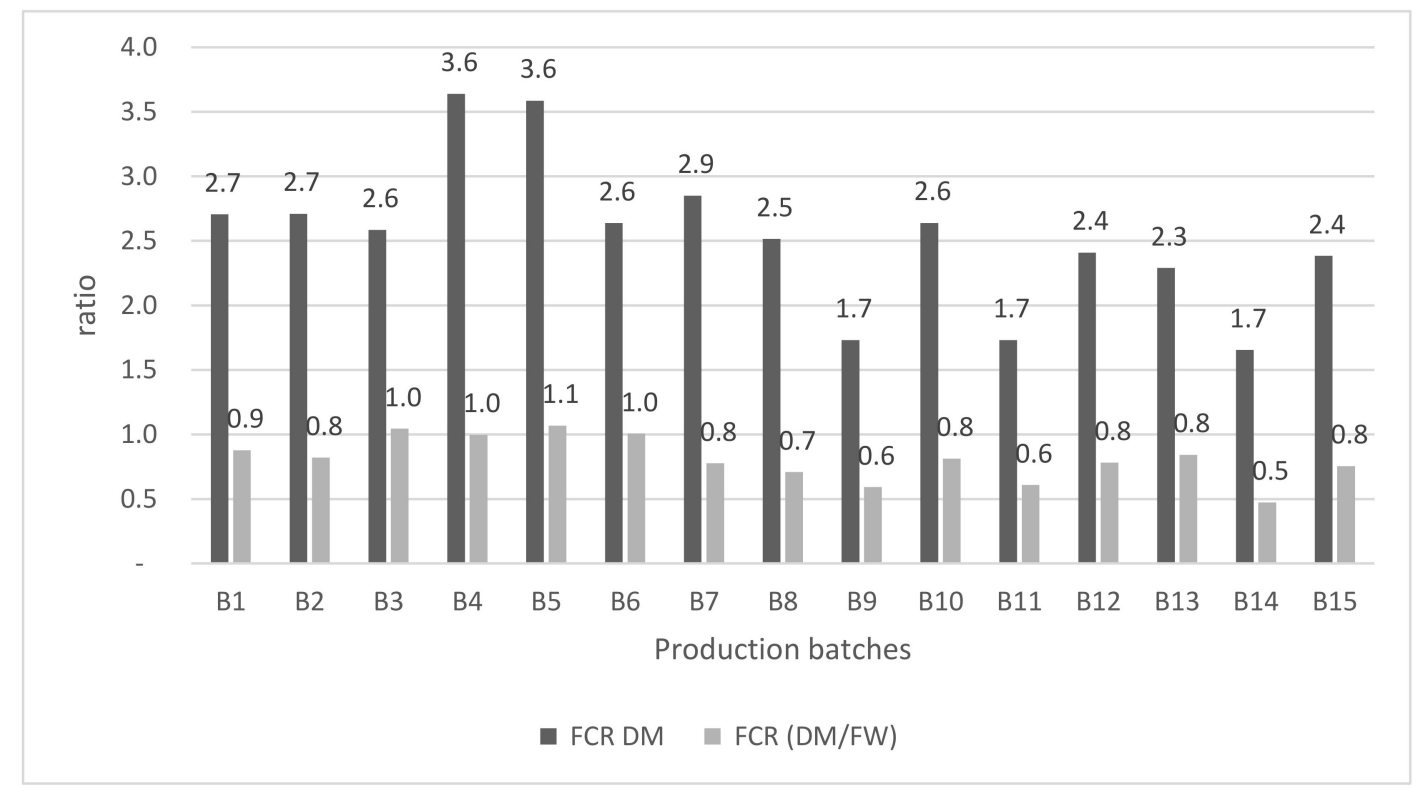

Figure 2. Feed conversion rate (FCR) obtained over 15 production batches (B1 to B15). The FCR is displayed on dry to wet (DM/FW) and dry to dry (DM) basis.

The performance of BSFL when fed two or five times during the production period was found to lead to similar outputs in terms of larval and insect biomasses, FCR and biomass reduction. Thus, approximately 558 and $542 \mathrm{~g}$ of dried BSFL per tray were produced when larvae were fed two and five times, respectively. Similarly, approximately 551 and $513 \mathrm{~g}$ of dried insect frass per tray were obtained as a result of feeding the larvae two and five times, respectively. Moreover, a FCR of 2.4 (DM/DM basis) was obtained as a consequence of different feedings, while the biomass reduction was $57 \%$ and $60 \%$ (DM basis) when larvae were fed two and five times, respectively. The PCE was found to be $56 \%$ when BSFL were fed five times compared with BSFL fed twice, which encountered a PCE of 53\%. This led to an increase in PCE of 3\% as a result of increasing the feedings (Figure 3).

\subsection{Digestibility Study}

The mink were found to successfully consume the provided diets with only few feed residues: control: 99.1\%, low inclusion: 95.7\%, medium inclusion: 99.1\%, and high inclusion: 96.9\%. Moreover, the physical characteristics of the feces were found to be similar across all treatments, having a score of 2.3 (control), 2.0 (low inclusion), 2.2 (medium inclusion), and 2.0 (high inclusion).

The apparent total tract digestibility of BSFL crude protein was estimated to be $86.2 \%$, and the apparent total tract digestibility of crude fat was estimated to $90.4 \%$, while the apparent total tract digestibility of the calculated carbohydrate fraction (by proximate analysis) was found to be relatively low at $48.1 \%$ (Table 6). 

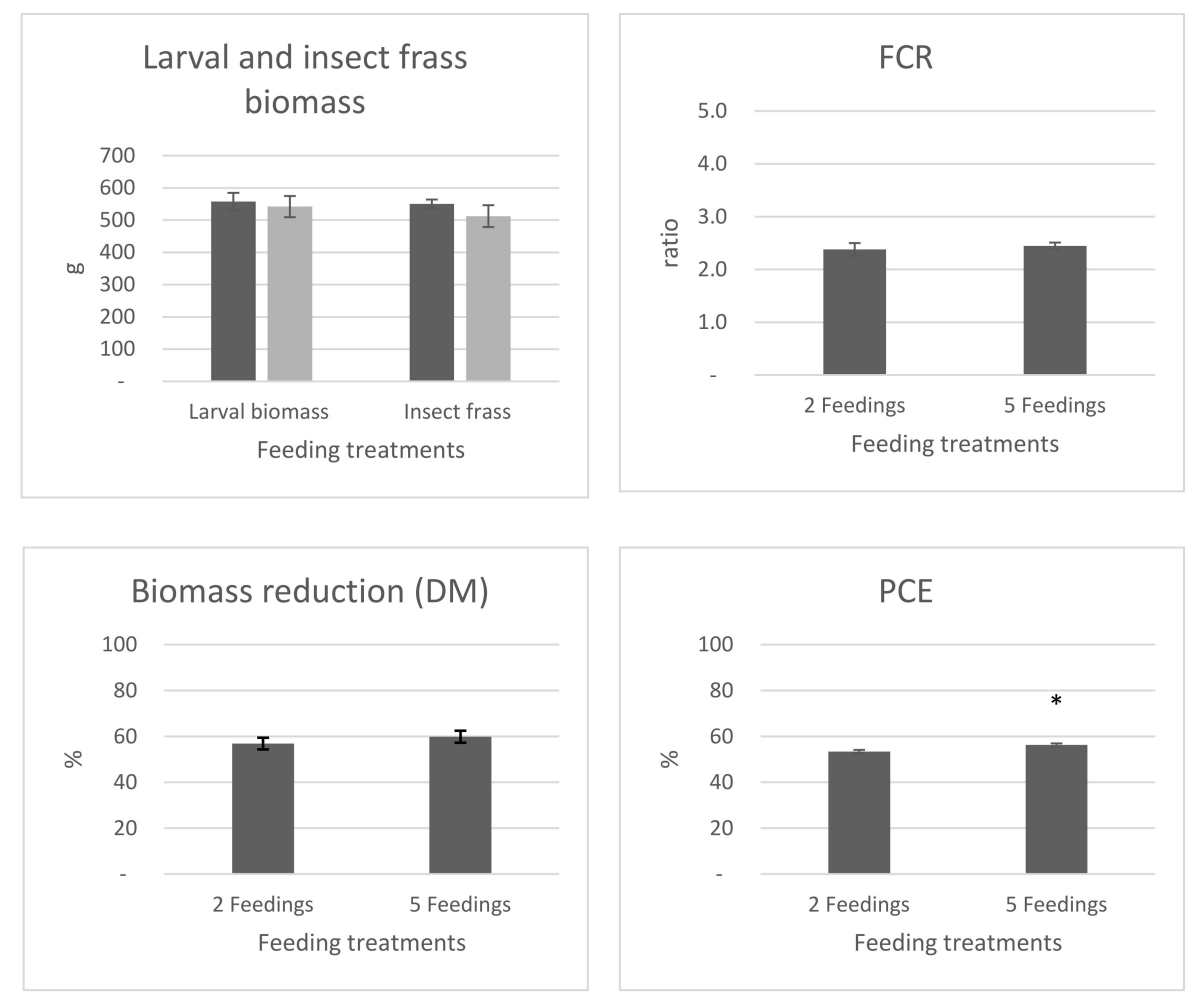

Figure 3. Larval and insect frass biomasses (upper left), FCR (upper right), biomass reduction (lower left) and PCE (lower right), mean and standard deviation. * Indicates significant differences among the feeding groups $(t$-test, $p<0.05)$.

Table 6. Estimates from regression analyzes, estimated total tract apparent digestibility of BSFL and standard error of mean (SEM).

\begin{tabular}{cccccc}
\hline & Observations & Intercept & Regression Coefficient & Estimated Digestibility & SEM \\
\hline Crude & 12 & 94.9 & -8.7 & 86.2 & 1.7 \\
protein & 11 & 97.9 & -7.5 & 90.4 & 0.5 \\
Fat & 12 & 94.6 & -46.6 & 48.1 & 9.1 \\
$\begin{array}{c}\text { Carbohydrate } \\
\text { (no cellulose) }\end{array}$ & & & & & \\
\hline
\end{tabular}

\section{Discussion}

The utilization of food waste as rearing substrate for BSFL has already demonstrated by other authors [23-26]. However, most of the studies are either conducted at laboratory scale or during single events and, consequently, could have limitations or be unreliable when implemented at industrial setup [9]. Consequently, the production of BSFL reared on food waste in an industrial relevant setup (pilot scale) and during multiple batches, conducted during the current project, provides additional information for industrial scale applications.

During the 14 months of pilot scale production, $190 \mathrm{~kg}$ DM of food waste was bioconverted into approximately $79 \mathrm{~kg}$ of DM BSFL, indicating that the utilization of food waste as rearing substrates for BSFL could be suitable at industrial scale. However, the quality of the rearing substrate such as nutrient composition and DM content is known to influence the development, performance and survival of BSFL [14]. Cheng et al. (2017) found that a decrease in food waste DM from 30 to $20 \%$ can decrease the larval development in approximately 5 days but will also make the separation process (larvae from insect frass) harder [27]. As discussed by Lalander et al. (2020), a decrease in DM content from 24 to $2.5 \%$ can lead to an increase in mortality associated with drowning, from approximately 3 to $81 \%$ [24]. The DM content may decrease the overall production output (larval biomass) because 
of a high migration rate and high mortality. Dortmans et al. (2017) recommend that in the case of a DM content lower than 15\%, the substrate should be dewatered, and an optimal DM of 20-30\% should be maintained for BSFL reared on food waste [28]. Similar to Dortmans et al. (2017), during this study, the DM was maintained between $15 \%$ and $23 \%$, using chicken feed as correction substrate. This procedure was found to not only increase the DM content but also to increase the porosity of the substrate, allowing the larvae to feed without risk of drowning. Furthermore, the DM ensured high larval production and short production time (8-10 days). The substrate macronutrient profiles (lipids, proteins, carbohydrates and fibers) are known to have the largest influence on the efficiency of the production and may vary across food waste [13]. Although the nutrient quality of the food waste was not considered for all the batches, with the exception of B 12 in which protein and fat content was analyzed, the production of BSFL on this substrate was found to be efficient, as indicated by the FCRs.

Overall, the FCR was found to be relatively low after Batch 5 (stabilization of the production) and to have a relatively low variation (1.7-2.9, FCR (DM)). To assess the replicability of BSFL performances during multiple batches (batches: 6-14) in terms of FCR, the coefficient of variation (CV) was estimated to be $19 \%$ for the FCR (DM) and 20\% for the FCR (DM/FW). Such relatively low CV suggests that the production of BSFL on biopulp can be replicated with high reproducibility. The FCRs obtained during our production were much lower compared to FCRs obtained by other studies [9]. Thus, the FCR obtained during the production of BSFL on municipal household waste was found to be 14.5. However, as the author discussed, the efficiency of this system was hardly affected by larval mortality associated with zinc contamination and high moisture content in the substrate. [29] Furthermore, Giannetto et al. (2020) obtained an FCR of 9.3 during the 5th instar and 12.5 at the prepupa stage of BSFL when reared on vegetable wastes [30].

The overall low FCR is hypothesized to be caused by the high quality of the biopulp with a balanced nutrient content (protein: as a result of being produced from diverse sources of food wastes (restaurants, canteens and households)) and at a high volume ( $>10$ tons/batch). Moreover, the nutrients in biopulp were highly accessible for BSFL because of fractionization and partly stabilized as a result of the fermentation procedure. However, although small FCR and high replicability were obtained during the pilot production, further optimization studies are required before utilizing the biopulp in commercial setups. These studies should aim for ensuring low FCRs and decreasing variation across batches, thus securing high and stable production outputs during commercial rearing. Moreover, further optimization studies should be considered for reducing the operational expense associated with maintenance and handling.

In this study, a feeding experiment was performed to assess the BSFL performance as a result of different feeding management, thus providing insight in optimizing the feeding while reducing the handling. During this experiment, we were able to bioconvert $8.7 \mathrm{~kg}$ of food waste (fresh weight) into $550 \mathrm{~g}$ larvae and $530 \mathrm{~g}$ insect frass (DM basis) per production tray over a period of 10 days. Similarly, Ermolaev et al. (2020) were able to bioconvert approximately $15 \mathrm{~kg}$ (fresh weight) of similar food waste into approximately $1 \mathrm{~kg}$ BSFL and $1 \mathrm{~kg}$ of insect frass (DM basis), respectively, per production tray over a period of 21 days [31], indicating that the production of BSFL on food waste can be achieved in different setups.

The production performance of BSFL associated with two and five feedings was found to be similar, except for PCE which was higher as a result of multiple feedings. Such results indicate that a decrease in handling, without affecting the production performance, can be obtained by reducing the feedings to two events. Banks et al. (2014) found that feeding the larvae every second day will result in smaller larvae and faster development time compared to one feeding, which leads to the production of larger larvae during a longer period. However, the increase in larval weight and development time is believed to be primely affected by alteration of substrate quality in case of one feeding. [32] The BSFL are known to have the highest feed intake during the latest stage of development during which reserves are accumulated as fats for ensuring successful metamorphosis to adults and for increasing the chance to reproduce [33]. However, in the case of low-quality substrates, as in the case of aged materials, 
the larvae are able to develop compensatory feeding in order to ensure that required nutrients for further development are ensured [32]. Thus, by administrating in the beginning and at a later stage (day 6 in this experiment), when larvae are in later development stages, the producer can ensure a fine balance between larval biomass output and the production time. Both biomass reduction and PCE were found to be high, with values over $50 \%$, indicating that high food waste reduction and protein recovery can be obtained as a result of bioconversion with BSFL.

The potential of BSFL for feeding carnivores was addressed by evaluation in mink. Mink are characterized by having a high demand for amino acids, a short gastro-intestinal tract with no caecum and thus a short digesta passage time little affected by microbial activity [34]. These factors result in the need for high-quality and highly digestible feedstuffs. Studies have shown that the mink is a suitable model animal for evaluation of small intestinal protein digestibility in dogs [35,36] and digestibility in rainbow trout [37] and Atlantic salmon [38], and thus the present results will be applicable for formulating pet food and fish feed with BSFL. The current results on total tract apparent digestibility point towards BSFL as excellent sources of crude protein and fat. The current findings of 86.2 and $90.4 \%$ exceed or match those found recently for fish meal by Tjernbekk et al. (2019) of 82.9 and $90.5 \%$ apparent total tract digestibility of crude protein and fat, respectively, as well as the commonly used poultry meal with 74.8 and $81.0 \%$ apparent total tract digestibility [39]. The carbohydrate digestibility, however, was low, and this may be caused by the chitin content of BSFL being accounted as carbohydrate in the proximate nutrient analysis and chitin being resistant to digestion by the animals' own enzymes, thus depending on microbial fermentation [40] which is low in mink.

Although the bioconversion of food wastes into high-quality BSFL can be successfully used as feed for pet food, the utilization of food waste as rearing substrate for insects is subjected to a series of constrains and requires further clarifications. The classification of whether a certain substrate is waste or not has large regulatory implications regarding whether it is legal to use as a feed material for farmed animals. Since 2017, seven species of insects, including H. illucens, Tenebrio molitor and Musca domestica, have been defined as farmed animals by the European Commission and are, therefore, subject to legal requirements regarding general food law and feed hygiene to be compliant on the EU market. At present, former foodstuffs containing meat and fish, catering waste and organic household waste are not legal to use as feed for insects in the EU. However, the EU regulatory framework for farmed animals has been constructed for vertebrates (e.g., fish, poultry, pigs, and cattle), and insects are, as invertebrates, very different from the relatively small group of animals that constitute and dominate current animal farming. For instance, when it comes to feed safety some of the relevant species in insect farming appear to have biological competences that can overcome some of the regulatory barriers that have been implemented to secure the food production system. There is increasing evidence that $H$. illucens has the ability to perform biosanitation on substrates that contain pathogen microorganisms [41]. The biological mechanism behind this ability appears to be caused by a high enzymatic activity in the larval gut as well as an intersectional difference in $\mathrm{pH}$ throughout the gut (ranging from approximately $\mathrm{pH} 2$ to 8). Additionally, this is further supported by various defensive mechanisms including different antimicrobial peptides (AMPs) that help to control potentially harmful microorganisms [29,42]. Moreover, several studies provide support of detoxification of certain pollutants [43] as well as degradation of some mycotoxins [44], while there is also evidence of bioaccumulation of certain metals [45]. These biological competences are as such not unique only to $H$. illucens but have also been observed in other species like M. domestica [46].

Currently, the European insect producers, organized by the trade association IPIFF, aim to get former foodstuff containing meat and fish legalized as feed for insects, and there is hope regarding the biosanitation potential of certain insect species such as H. illucens. However, a lot of evidence still needs to be provided, not least at demonstration scale, prior to obtaining approval in the EU for using insects fed on organic wastes for application as, for example, pet food or fish feed. 


\section{Conclusions}

Circular economy has become one of the most important research themes worldwide, supporting sustainable and resource-efficient policies for long-term socio-economic and environmental benefits. Currently, the food waste in the form of biopulp is used for energy production (biogas); however, this is rather seen as a downcycle since valuable biomolecules (amino acids, vitamins, etc.) are converted into energy. The biopulp was efficiently bioconverted into high-quality BSFL biomass during multiple batches, indicating that organic household waste and catering waste are suitable substrates for insect production. Furthermore, the results showed high digestibility of crude protein and fat, which can ensure that BSFL reared on food waste streams can be successfully used as feed component for animals outside the food chain, but assumingly also in aquaculture. Consequently, the results demonstrate that food waste can be successfully applied as the main feed insect production intended to be used as feed outside the food chain. Our recommendation to legislators, particularly in Europe, is to fast-track research in feed safety of underutilized and currently illegal substrates-e.g., catering waste and former foodstuffs containing meat and fish. Hence, prioritizing and supporting the industrial insect sector with a unique opportunity that is a "match made by nature".

Author Contributions: Conceptualization, A.G., C.H.F. and L.-H.L.H. Investigation, A.G., C.H.F. and P.F.L., Visualization, P.F.L. and L.-H.L.H., Writing-Original draft, A.G., Writing-Review \& editing, A.G., C.H.F., P.F.L., J.V.N. and L.-H.L.H., Supervision, L.-H.L.H. All authors have read and agreed to the published version of the manuscript.

Funding: This paper is carried out from the research project "Waste Insects and Circular Economy (WICE)" funded by the Danish Environmental Protection Agency's Environmental Technology Development and Demonstration Program (MUDP).

Acknowledgments: We would like to thank the Danish Environmental Protection Agency for funding the Waste Insects and Circular Economy project (MST 141-001193) and thus contributing consistently to the realization of this study.

Conflicts of Interest: The authors declare no conflict of interest.

\section{References}

1. Food and Agriculture Organization; International Fund for Agricultural Development; United Nations Children's Fund; World Food Programme; World Health Organization. Executive summary. In The State of Food Security and Nutrition in the World 2020. Transforming Food Systems for Affordable Healthy Diets; Food and Agriculture Organization: Rome, Italy, 2020.

2. Perrino, E.V.; Perrino, P. Crop wild relatives: Know how past and present to improve future research, conservation and utilization strategies, especially in Italy: A review. Genet. Resour. Crop Evol. 2020, 67, 1067-1105. [CrossRef]

3. Food and Agriculture Organization. Food Wastage Footprint: Impacts on Natural Resources (Summary Report); Food and Agriculture Organization: Rome, Italy, 2013; pp. 1-63.

4. Food and Agriculture Organization. Extent of food losses and waste. In Global Food Losses and Food Waste—Extent, Causes and Prevention; Food and Agriculture Organization: Rome, Italy, 2011; pp. 4-9.

5. CONCITO. Klimagevinster Ved Øget Proteinproduktion i Danmark. 2014. Available online: https: //concito.dk/udgivelser/klimagevinster-ved-oget-proteinproduktion-danmark (accessed on 24 March 2020).

6. EUROSTAT. Generation of Waste by Waste Category, Hazardousness and NACE Rev, 2 Activity. Available online: https://ec.europa.eu/eurostat/databrowser/view/env_wasgen/default/table?lang=en (accessed on 24 November 2020).

7. Danish Environmental Protection Agency. Denmark Without Waste. 2013. Available online: https: //eng.mst.dk/air-noise-waste/waste/denmark-without-waste/ (accessed on 25 March 2020).

8. Van Huis, A.V.; Van Itterbeeck, J.; Klunder, H.; Mertens, E.; Halloran, A.; Muir, G.; Vantomme, P. Edible Insects-Future Prospects for Food and Feed Security. FAO Forestry Paper 171. 2013. Available online: http://www.fao.org/3/i3253e/i3253e00.htm (accessed on 27 March 2020). 
9. Surendra, K.C.; Tomberlin, J.K.; Van Huis, A.; Cammack, J.A.; Heckmann, L.H.; Khanal, S.K. Rethinking organic wastes bioconversion: Evaluating the potential of the black soldier fly (Hermetia illucens (L.)) (Diptera: Stratiomyidae) (BSF). Waste Manag. 2020, 117, 58-80. [CrossRef] [PubMed]

10. Newton, L.; Sheppard, C.; Watson, W.; Burtle, G.; Rober, D. Using the Black Soldier Fly, Hermetia illucens, as a Value-Added Tool for the Management of Swine Manure; Animal and Poultry Waste Management Center, North Carolina State University: Raleigh, NC, USA, 2005.

11. Diclaro, J.W.; Kaufman, P.E. Black Soldier Fly Hermetia illucens Linnaeus (Insecta: Diptera: Stratiomyidae). EENY 2009, 461, 1-4.

12. Lalander, C.; Diener, D.; Zurbrügg, C.; Vinnerås, B. Effects of feedstock on larval development and process efficiency in waste treatment with black soldier fly (Hermetia illucens). J. Clean. Prod. 2019, 208, 211-219. [CrossRef]

13. Gold, M.; Tomberlin, J.K.; Diener, S.; Zurbrugg, C.; Mathys, A. Decomposition of biowaste macronutrients, microbes, and chemicals in black soldier fly larval treatment: A review. Waste Manag. 2018, 82, 302-318. [CrossRef] [PubMed]

14. Singh, A.; Kumari, K. An inclusive approach for organic waste treatment and valorization using black soldier fly larvae: A review. J. Environ. Manag. 2019, 251, 109569. [CrossRef]

15. Makkar, H.P.S.; Tran, G.; Heuze, V.; Ankers, P. State-of-the-art use of insects as animal feed. Anim. Feed Sci. Technol. 2014, 197, 1-33. [CrossRef]

16. Wang, Y.; Shelomi, M. Review of black soldier fly (Hermetia illucens) as animal feed and human food. Foods 2017, 6, 91. [CrossRef]

17. Barragan-Fonseca, K.B.; Dicke, M.; Van Loon, J.J.A. Nutritional value of the black soldier fly (Hermetia illucens L.) and its sustainability as animal feed-A review. J. Insects Food Feed 2017, 3, 105-120. [CrossRef]

18. Smetana, S.; Schmitt, E.; Mathys, A. Sustainable use of Hermetia illucens insect biomass for feed and food: Attributional and consequential life cycle assessment. Resour. Conserv. Recycl. 2019, 144, 285-296. [CrossRef]

19. Oonincx, D.G.A.B.; Van Broekhoven, S.; Van Huis, A.; Van Loon, J.J.A. Feed conversion, survival and development, and composition of four insect species on diets composed of food by-products. PLoS ONE 2015, 10, 0144601. [CrossRef] [PubMed]

20. Gao, Z.; Wang, W.; Lu, X.; Zhu, F.; Liu, W. Bioconversion performance and life table of black soldier fly (Hermetia illucens) on fermented maize straw. J. Clear Prod. 2019, 230, 974-980. [CrossRef]

21. Liu, X.; Chen, X.; Wang, H.; Yang, Q.; Ur Rehman, K.; Li, W.; Cai, M.; Li, Q.; Mazza, L.; Zhang, J.; et al. Dynamic changes of nutrient composition throughout the entire life cycle of black soldier fly. PLoS ONE 2017, 12, 0182601. [CrossRef] [PubMed]

22. Nalawade, V.B.; Bhilave, M.P.; Kulkarni, J.J. Protein conversion efficiency (PCE) in muscle of freshwater fish Labeo rohita fed on formulated feed. Biol. Forum Int. J. 2014, 6, 79-83.

23. Liu, T.; Awasthi, M.K.; Awasthi, S.K.; Duan, Y.; Zhang, Z. Effects of black soldier fly larvae (Diptera: Stratiomyidae) on food waste and sewage sludge composting. J. Environ. Manag. 2020, 256, 109967. [CrossRef]

24. Lalander, C.; Ermolaev, E.; Wiklicky, V.; Vinnerås, B. Process efficiency and ventilation requirement in black soldier fly larvae composting of substrates with high water content. Sci. Total Environ. 2020, 729, 138968. [CrossRef]

25. Diener, S.; Zurbrügg, C.; Gutiérrez, F.R.; Nguyen, D.H.; Morel, A.; Koottatep, T.; Tockner, K. Black soldier fly lavae for organic waste treatment-Prospects and constraints. In Proceedings of the 2nd International Conference on Solid Waste Management in the Developing Countries, Khulna, Bangladesh, 13-15 February 2011.

26. Nguyen, T.T.X.; Tomberlin, J.K.; Vanlaerhoven, S. Influence of resources on Hermetia illucens (Diptera: Stratiomyidae) larval development. J. Med Entomol. 2013, 50, 898-906. [CrossRef]

27. Cheng, J.K.L.; Chiu, S.L.H.; Lo, I.M.C. Effects of moisture content of food waste on residue separation, larval growth and larval survival in black soldier fly bioconversion. Waste Manag. 2017, 67, 315-332. [CrossRef]

28. Dortmans, B.; Diener, S.; Verstappen, B.M.; Zurbrügg, C. Black Soldier Fly Biowaste Processing: A Step-by-Step Guide; Swiss Federal Institute of Aquatic Science and Technology (Eawag): Dübendorf, Switzerland, 2017; pp. 10-48.

29. Diener, S.; Solano, N.M.S.; Gutiérrez, F.R.; Zurbrügg, C.; Tockner, K. Biological treatment of municipal organic waste using black soldier fly larvae. Waste Biomass Valoriz. 2011, 2, 357-363. [CrossRef] 
30. Giannetto, A.; Oliva, S.; Lanes, C.F.C.; De Araujo Pedron, F.; Savastano, D.; Baviera, C.; Parrino, V.; Lo Paro, G.; Spano, N.C.; Cappello, T.; et al. Hermetia illucens (Diptera: Stratiomydae) larvae and prepupae: Biomass production, fatty acid profile and expression of key genes involved in lipid metabolism. J. Biotechnol. 2019, 307, 44-54. [CrossRef]

31. Ermolaev, E.; Dahlquist, E.; Lalander, C.; Vinnerås, B.; Thorin, E. Model selection for waste conversion efficiency and energy demands in a pilot for large-scale larvae treatment. In Proceedings of the 60th SIMS Conference on Simulation and Modelling SIMS, Västerås, Sweden, 12-16 August 2019.

32. Banks, I.J.; Gibson, W.T.; Cameron, M.M. Growth rates of black soldier fly larvae fed on fresh human faeces and their implication for improving sanitation. Trop. Med. Int. Health 2014, 19, 14-22. [CrossRef] [PubMed]

33. Gligorescu, A.; Toft, S.; Hauggaard-Nielsen, H.; Axelsen, J.A.; Nielsen, S.A. Development, growth and metabolic rate of Hermetia illucens larvae. J. Appl. Entomol. 2019, 143, 875-881. [CrossRef]

34. Skrede, A. Utilization of fish and animal byproducts in mink nutrition. Acta Agricult. Scand. 1979, 29, 241-257. [CrossRef]

35. Vhile, S.; Skrede, A.; AhlstrØm, Ø.; Hov, K. Comparative apparent total tract digestibility of major nutrients and amino acids in dogs (Canis familiaris), blue foxes (Alopex lagopus) and mink (Mustela vison). Anim. Sci. 2005, 81, 141-148. [CrossRef]

36. Tjernsbekk, M.T.; Tauson, A.; Ahlstrøm, Ø. Ileal, colonic and total tract nutrient digestibility in dogs (Canis familiaris) compared with total tract digestibility in mink (Neovison vison). Arch. Anim. Nutr. 2014, 68, $245-261$. [CrossRef]

37. Øverlandab, M.; Romarheima, O.H.; Hovin, M.; Storebakken, T.; Skrede, A. Apparent total tract digestibility of unprocessed and extruded diets containing basic and autolyzed bacterial protein meal grown on natural gas in mink and rainbow trout. Anim. Feed Sci. Technol. 2006, 129, 237-251. [CrossRef]

38. Skrede, A.; Berge, G.M.; Storebakken, T.; Herstada, O.; Aarstad, K.G.; Sundstøl, F. Digestibility of bacterial protein grown on natural gas in mink, pigs, chicken and Atlantic salmon. Anim. Feed Sci. Technol. 1998, 76, 103-116. [CrossRef]

39. Tjernsbekk, M.T.; Tauson, A.; Matthiesen, C.F.; Ahlstrøm, Ø. Amino acid availability of protein meals of different quality for adult and growing mink (Neovison vison). Arch. Anim. Nutr. 2020, 74, 72-86. [CrossRef]

40. Khempaka, S.; Chitsatchapong, C.; Molee, W. Effect of chitin and protein constituents in shrimp head meal on growth performance, nutrient digestibility, intestinal microbial populations, volatile fatty acids, and ammonia production in broilers. J. Appl. Poult. Res. 2011, 20, 1-11. [CrossRef]

41. Lalander, C.; Diener, S.; Magri, M.E.; Zurbrugg, C.; Lindstrom, A.; Vinnerås, B. Faecal sludge management with the larvae of the black soldier fly (Hermetia illucens)—From a hygiene aspect. Sci. Total Environ. 2013, 458, 312-318. [CrossRef]

42. De Smet, J.; Wynants, E.; Cos, P.; Van Campenhout, L. Microbial community dynamics during rearing of black soldier fly larvae (Hermetia illucens) and impact on exploitation potential. Appl. Environ. Microbiol. 2018, 84, e02722-e02817. [CrossRef] [PubMed]

43. Lalander, C.; Senecal, J.; Calvo, M.C.; Ahrens, L.; Josefsson, S.; Wiberg, K.; Vinnerås, B. Fate of pharmaceuticals and pesticides in fly larvae composting. Sci. Total Environ. 2016, 565, 279-286. [CrossRef] [PubMed]

44. Bosch, G.; Van der Fels-Klerx, H.J.; De Rijk, T.C.; Oonincx, D.G.A.B. Aflatoxin B1 Tolerance and Accumulation in Black Soldier Fly Larvae (Hermetia illucens) and Yellow Mealworms (Tenebrio molitor). Toxins 2017, 9, 185. [CrossRef] [PubMed]

45. Proc, K.; Bulak, P.; Wiacek, D.; Bieganowski, A. Hermetia illucens exhibits bioaccumulative potential for 15 different elements-Implications for feed and food production. Sci. Total Environ. 2020, 723, 138125. [CrossRef]

46. Nordentoft, S.; Fischer, C.; Bjerrum, L.; Heckmann, L.H.; Hald, B. Reduction of Escherichia coli, Salmonella Enteritidis and Campylobacter jejuni in poultry manure by rearing of Musca domestica fly larvae. J. Insects Food Feed 2017, 3, 145-153. [CrossRef]

Publisher's Note: MDPI stays neutral with regard to jurisdictional claims in published maps and institutional affiliations. 